\title{
Investigating Appropriate Financing Methods in Collaborative Projects of Water and Wastewater with AHP Approach
}

\author{
Vandad Vosoughi \\ Department of Civil Engineering \\ Nour Branch, Islamic Azad \\ University, Nour, Iran. \\ vandadvosoughi@gmail.com
}

\author{
Heydar Dashti Nasserabadi \\ Department of Civil Engineering \\ Chalus Branch, Islamic Azad \\ University, Chalus, Iran \\ Dashti@iauc.ac.ir
}

\author{
Abbas Babaei \\ Department of Civil Engineering \\ Nour Branch, Islamic Azad \\ University, Nour, Iran \\ Ababaei@iaunour.ac.ir
}

\begin{abstract}
A mix of public and private funding is employed worldwide to enable the construction of large public projects and even, in some cases, the work of public services. In this study, the selected methods of financing of participatory projects of water and water wastes were studied and prioritized. Questionnaires and comments of experts were used along with AHP decisionmaking and Expert Choice software. Different financing methods include: BOT and BOO and its types, the publication of bonds, foreign direct investment, the method of buyback, internal financing, current financing, development banks, Barter transactions, new tax resources and foreign financing. Results are shown and discussed and a final ranking is provided.
\end{abstract}

Keywords-financing; public-private partnership contracts; water and sanitation projects; $A$ HP methods

\section{INTRODUCTION}

With rapid population growth and the increasing need for drinking water and wastewater disposal, in most countries, the governments are obliged to carry out infrastructure projects. Historically, public funds were used for such projects. However, the past years a mixed (public and private) funding is followed in most such cases [1]. The justification for private participation in the funding is the state's financial situation, the ability to move forward multiple projects and the high expertise that private sector is supposed to offer [2]. The original contract is between the public and private parties. The participation contract is the risk divider between associated risks with the projects of the parties and is determined by the general conditions of the assignment, tariffs, and payments, regulations and performance standards for the design, construction, operation and maintenance of constructions. Public Private Partnership (PPP) is a model in which, the government-sector in partnership with the private sector, attempt to design, implement, manage and support large projects [3]. Public-Private Partnership includes a contract that takes place between a governmental agency and a private party in which the parties are involving in using their abilities and assets, to provide services and facilities and public use. In addition to the sources, the participation takes place in the risk sharing and harvesting interests [4].

\section{METHOD LAYOUT SCHEME}

A research method includes the set of rules, the tools, the reliable and systematic ways for achieving solutions [5]. In this research, suitable financing methods for participatory projects of water and water waste projects are investigated, considering the special characteristics of such projects. For this purpose, some criteria for evaluating the types of financing methods is introduced and explained. Ten such methods are chosen and indicators are introduced through a questionnaire handed to experts in this area. Results are analyzed using Expert Choice software.

\section{A. Effective indicators}

The effective indicators were identified using a set of literature review and case studies.

\section{1) Efectiveness area}

The effect's value of water and water waste projects on its climate conditions has a direct relationship with the desired objectives from the implementation of the plan. Plans for water are designed for a specific region (directly) but the impact weighs in the whole country (indirectly), thus the effectiveness area is both the region and the country [6].

\section{2) Fairness}

The fair term reflects the fact that the preparation of required funds to build infrastructure facilities should be divided fairly between the consumers. This means that everyone to the extent that benefited from this structure (direct and indirect users), must pay its fee [6]. From this perspective, the method of selling products is considered as the fairest method. As the payment groups to move away from the circle of direct consumers, the fairness value is reduced [6].

\section{3) Effectiveness}

During the process of choosing a financing method, the impact on the project's success and the development of the near 
area is to be considered. However, additional care should be provided so that the extra costs are not imposed on the consumers [6]. Correlating the level of satisfaction to the price is a well established method [7]. Whatever the difference between the cost that satisfies the consumers and the actual cost, the consumers will most likely try to modify the conditions to their advantage [8]. In the ideal case that no difference is documented, the value of this index is set to 1 .

\section{4) Financial sustainability}

The values of stability and sustainability of used resources are also to be considered (8). The main focus of the project executive is on the determining the fluctuations in the resources of the selected method. Several factors are involved in causing these fluctuations and the result of activating these factors is imposing additional costs to the project. The most prominent risks during the financing of a project, can be divided into 5 main groups: political, financial, construction, risks, operational and market [8].

\section{B. Financing methods}

In this study, to evaluate the most appropriate method of financing, ten methods are considered. These are the following:
(1) new tax resources, (2) current finance payback method, (3) barter transactions, (4) foreign investors, (5) bonds, (6) internal financing, (7) buyback methods, (8) BOT, BOO etc, (9) development banks, (10) Foreign Direct Investment.

\section{Familiarity with AHP analytical method}

Analytical Hierarchy Process (AHP) method is a multicriteria decision-making technique. This method can be rather useful when faced with few options and decision criteria. Indicators can be quantitative or qualitative. The basis of this method is pair comparisons [9].

The process of ranking and prioritization of options in AHP methods includes the following steps:

1) Setting the Hierarchy

At this stage, the problem is defined and the purpose of decision-making is drawn with a hierarchy of factors and elements of the decision. For this purpose, a decision tree is used [9] (Figure 1).

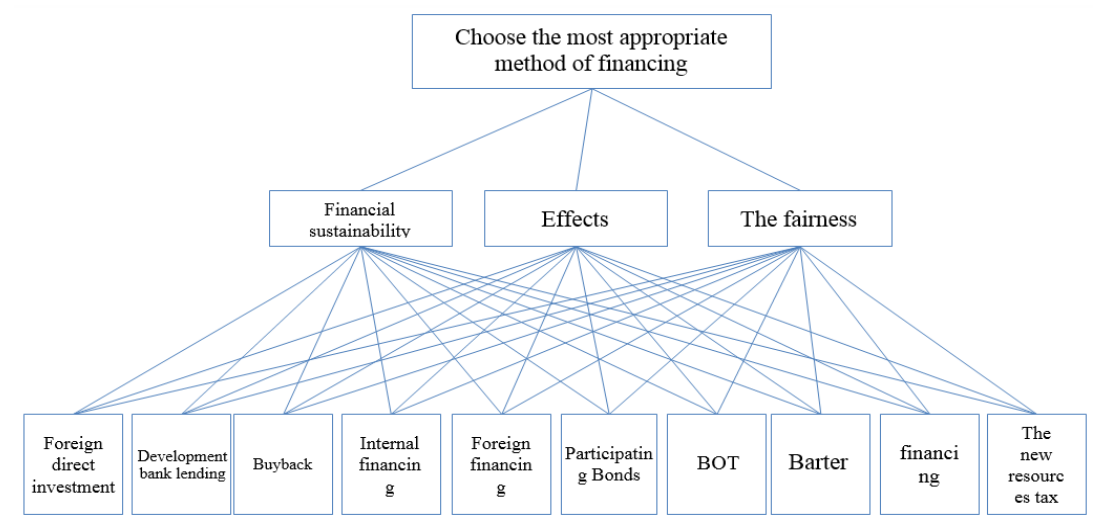

Fig. 1. Making hierarchy Determine the most appropriate method of financing

\section{2) Paired comparisons}

At this stage, the experts make comparisons between scales and sub-scales of decision making and determine its scores to each other.

3) Calculation of relative weight

The next step in the Analytic Hierarchy Process (AHP) is the required calculations to determine the priority of any decision elements by using the information of the matrixes of paired-calculations.

\section{4) The final weigh of options}

The final weight of options is obtained from the sum of criteria importance in the weight of options (9).

5) Calculation of data validation (incompatible rates)

Inconsistency rate (I.R.), is a mechanism by which the validity of the answers of respondents to the pair wise comparisons is measured. Almost all the AHP calculations based on a preliminary judging decision that appears in the form of pairwise comparison matrix and any error and incompatibility between options and indicators would skew the final obtained results of calculations [9].

\section{Questionnaires}

\section{1) Structure}

The questionnaire includes a set of Frequently Asked Questions that by utilizing various scales, comment, perspective, and insight of individuals assesses the respondent. The measurement scale is a set of principles for assigning the subjects to the category or assigning the figures to the subjects. The relative scale has been chosen as the used scale in the questionnaire. Relative scale is the most precise scale for measurement. This scale has a value of true zero that is a point on the scale that shows a complete shortage of the features on measurement. By this scale either the difference between the figures and their relative importance could be compared [10]. 


\section{2) Validity}

Standard questionnaires were used in this study and after receiving the comments of the experts in the stage of validation, the accuracy, clarity, and transparency of made questions, were revised and the questionnaires were prepared for distribution.

\section{3) The sample size}

In order to obtain the opinions of the experts, 20 questionnaires were distributed between them. Among the distributed questionnaires, 14 of them were returned. 5 numbers of questionnaires due to defects in completion and improper method of inserting information were excluded from the analysis process. Therefore, the analysis was conducted on the remaining 9 questionnaires.

\section{4) Limitations in information gathering}

Data collection from different experts involved in different projects is bound to face constraints due to confidentiality. personal involvement is also an issue.

\section{5) Reliability}

One of the most well known methods for calculating reliability is using Cronbach's alpha. The method is used for calculating the internal consistency of measurement tools, including questionnaires. Cronbach's alpha has been used to determine the reliability of the questionnaire with emphasis on internal consistency. Provided that the alpha coefficient is more than 0.7 the test has acceptable reliability.

\section{6) Analysis of questionnaire data}

The AHP method is used for converting the qualitative comments of experts to quantitative values that can be calculated and compared. For ranking, all questions were summarized in the form of four separate matrices, then the different AHP methods were implemented on the data. The raw data was analyzed using Expert Choice software.

\section{RESULTS}

The Expert Choice software results for each of the comparison criteria and for the questionnaire of AHP coefficient is shown in Figures 2 to 6 and Tables I to V. As it can be seen the participatory methods such as BOT, BOO have the highest value. The mean, variance and standard deviation (std) of the available data for each indicator are also calculated. An overall comparison is given in Figure 7.

\section{CONCLUSION}

In this study, ten methods of financing for water and water wastes projects were studied and prioritized. Questionnaires were used along with AHP decision-making and Expert Choice software. The final ranking is as follows: (1) BOT, BOO etc, (2) bonds, (3) Foreign direct investment, (3) buyback, (4) internal financing, (5) current financing, (6) developmental banks, (7) Barter transactions, (8) New tax resources, (10) Financing from foreign finance.

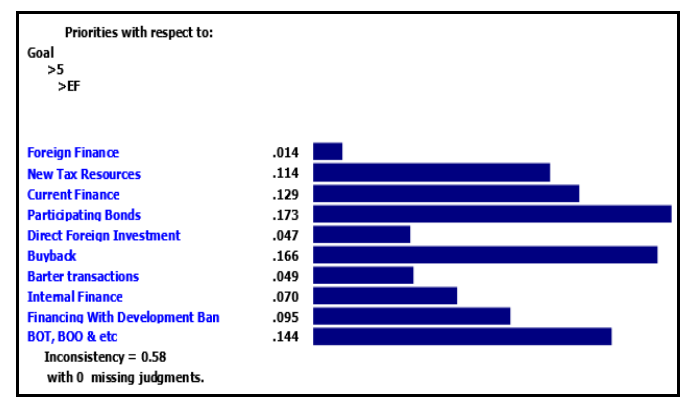

Fig. 2. Ranking based on effectiveness

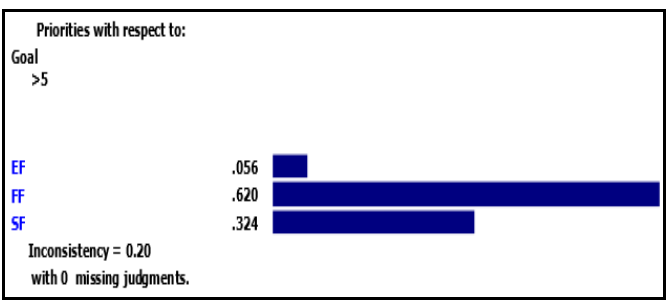

Fig. 3. Comparison

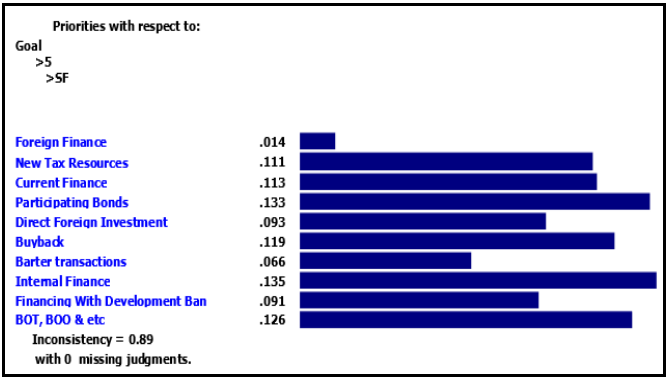

Fig. 4. Ranking on fairness

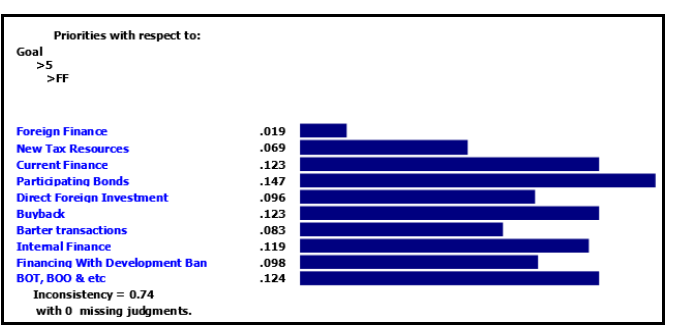

Fig. 5. Ranking on financial sustainability

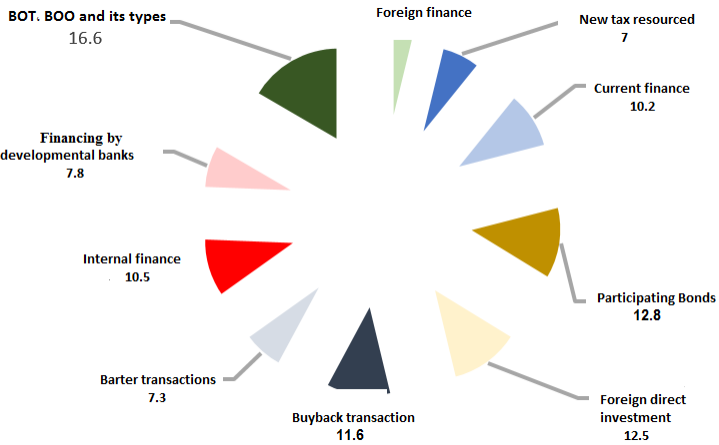

Fig. 6. methods 
TABLE I. AHP COEFFICIENTS DERIVED FROM THE ANALYSIS CRITERIA

\begin{tabular}{|c|c|c|c|c|c|c|c|c|c|c|}
\hline Number of questionnaire & 1 & 2 & 3 & 4 & 5 & 6 & 7 & 8 & 9 \\
\hline Effectiveness & 0.064 & 0.073 & 0.078 & 0.17 & 0.056 & 0.99 & 0.08 & 0.187 & 0.379 \\
\hline Fairness & 0.237 & 0.205 & 0.205 & 0.123 & 0.62 & 0.537 & 0.609 & 0.07 & 0.508 \\
\hline Sustainability & 0.699 & 0.722 & 0.722 & 0.707 & 0.324 & 0.364 & 0.311 & 0.743 & 0.113 \\
\hline
\end{tabular}

TABLE II. TOTAL OBTAINED AHP COEFFICIENT FOR EACH FINANCING METHOD

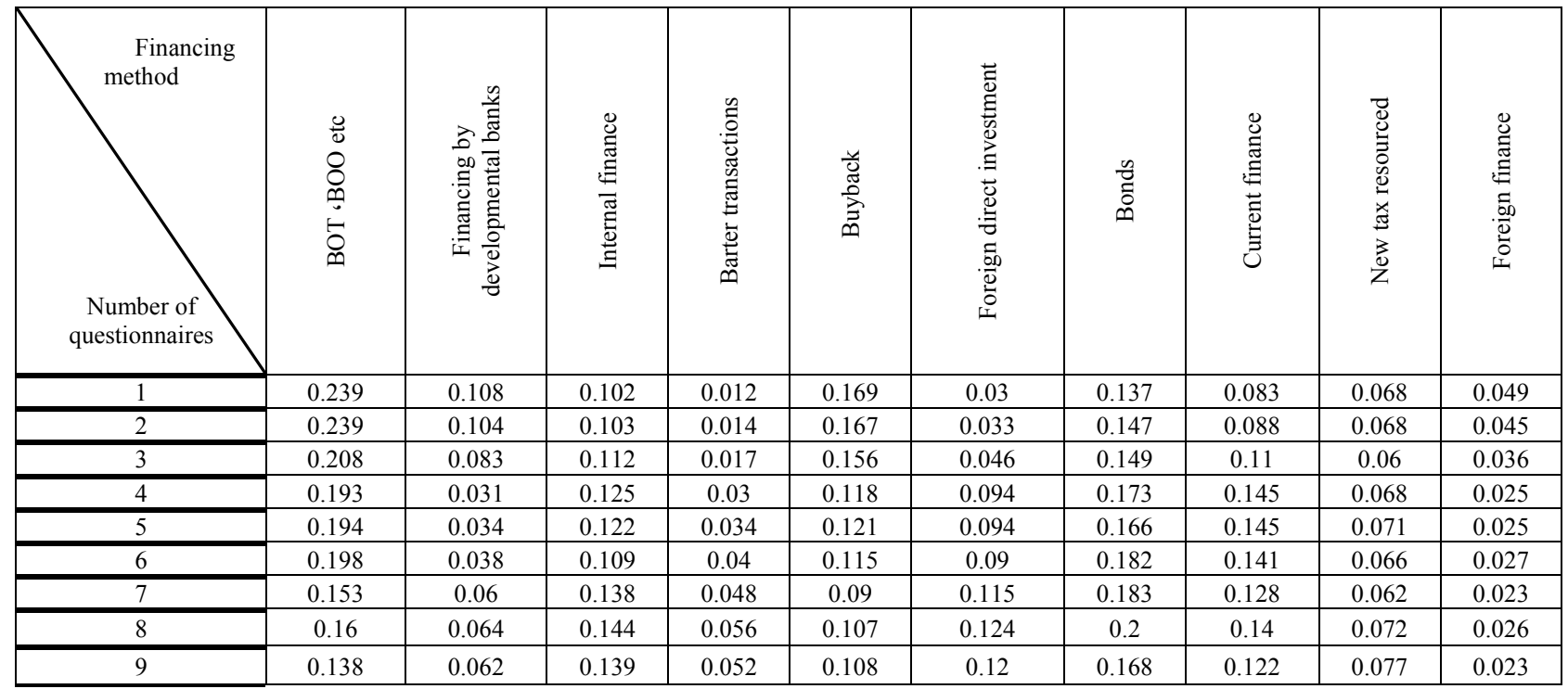

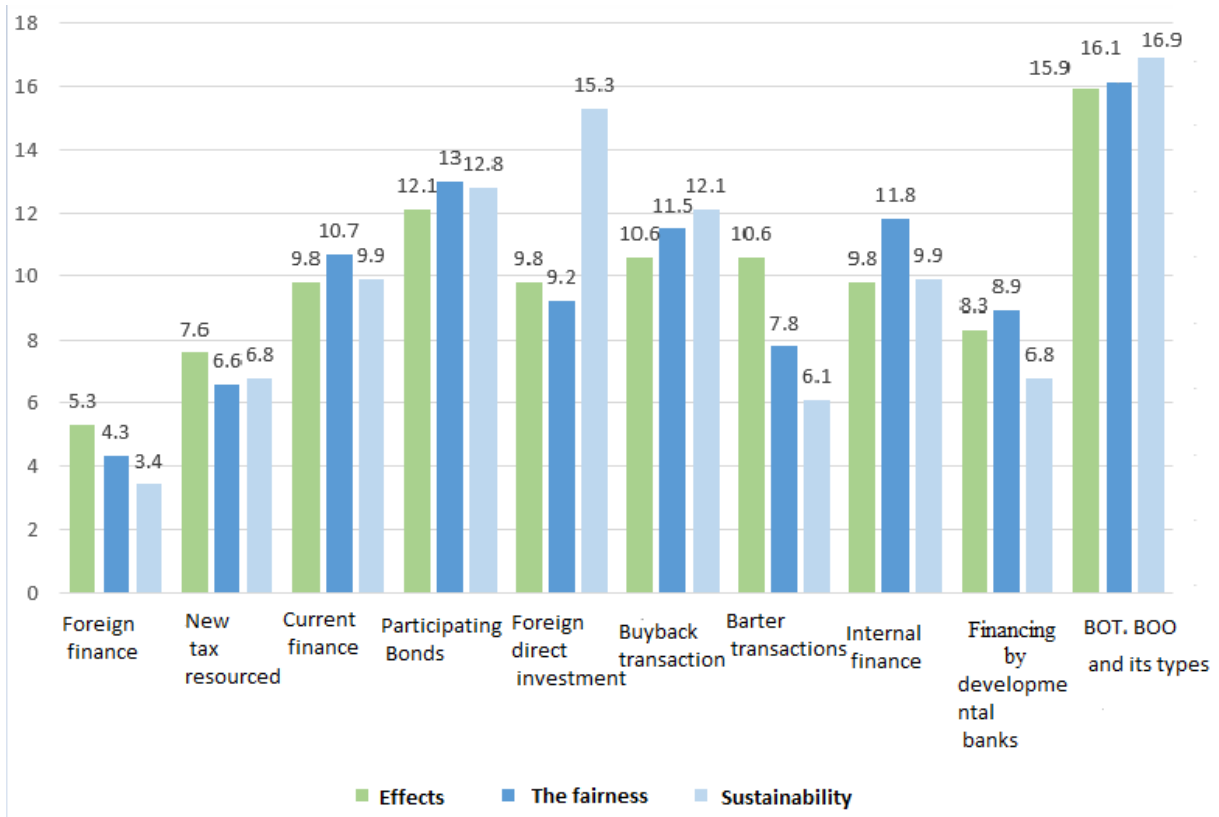

Fig. 7. Overall comparison

TABLE III. THE SCORES OF COMPARING INDEXES

\begin{tabular}{|c|c|c|c|}
\hline & Sustainability & Fairness & Effects \\
\hline $\begin{array}{c}\text { Average score for each } \\
\text { indicator }\end{array}$ & 0.467 & 0.346 & 0.132 \\
\hline Percentage of each indicator & 49.4 & 36.60 & 14 \\
\hline
\end{tabular}

TABLE IV. COMPARING INDICES

\begin{tabular}{|c|c|c|c|}
\hline & sustainability & Fairness & Effects \\
\hline Variance & 0.052 & 0.043 & 0.0096 \\
\hline $\begin{array}{l}\text { Standard } \\
\text { deviation }\end{array}$ & $23.47 \%$ & $20.67 \%$ & $9.78 \%$ \\
\hline
\end{tabular}


TABLE V. THE VALUES OF MEAN, VARIANCE AND STANDARD DEVIATION FOR FINANCING METHODS

\begin{tabular}{|c|c|c|c|c|c|c|c|}
\hline Financing method & mean & var & std (\%) & Financing method & mean & var & std (\%) \\
\hline BOT, BOO etc & 0.17 & 0.0011 & 3.38 & internal finance & 0.10 & 0.0012 & 3.4 \\
\hline Bonds & 0.13 & 0.001 & 3.16 & Buyback & 0.08 & 0.0006 & 2.5 \\
\hline Current finance & 0.12 & 0.001 & 3.16 & Foreign Direct Investment & 0.07 & 0.0014 & 3.7 \\
\hline Development banks & 0.11 & 0.0009 & 3.02 & Using foreign finance & 0.07 & 0.0003 & 1.7 \\
\hline New tax resources & 0.11 & 0.00055 & 2.54 & Barter transactions & 0.04 & 0.003 & 1.7 \\
\hline
\end{tabular}

\section{REFERENCES}

[1] M. G. R. H. Falamaryzi, "The Treaty on public-private partnership (public-private partnership) in infrastructure projects", Sixth International Conference on Project Management, Tehran, Iran, 2010.

[2] Management and Planning Organization, Public-Private Partnership Framework Agreement, 201.

[3] H. Ashkuh, M. H. Sobhieh, H. S. Zargarpur, P. Zarabad, "The challenges of financing power projects in public-private partnership", Sixth Conference of Financial System Development in Iran, Tehran, Iran, 2013

[4] S. M. Mousavi, M. Ahmedi, R. Farhadi, "Pathology providing publicprivate partnership approach", Municipal Finance Conference, Tehran, Iran, 2010

[5] E. Seyed Hoseini, Review of contracts in the free zones development projects (case study: Kish Free Zone), MSc Thesis, University of Isfahan (Khorasgan), Iran, 2015

[6] M. A. Saglio, Financing Public Infrastructure in the United States and France; A Comparative Analysis and policy Recommendations, MSc. Thesis, Massachusetts Institute of Technology, USA, 1995

[7] J. Krajne, "Cost Recovery Vs. marginal social cost toll calculation Motorway operator's Perspective", SECAP PULA, 2006, Slovenia.

[8] M. S. Miri,. New methods of financing highway projects and provide appropriate manner, MSc thesis, Civil Engineering and Construction Management Engineering, University of Technology (Tehran Polytechnic), 2008.

[9] S. H. Qodsipour, Discussions on multi-criteria decision-making, Amir Kabir University Press, 2002

[10] M. R. Ebrahiami,'Financial and economic evaluation", Committee Report No. 9 Pyark, Publications Center of Higher Education and Research Institute for Management and Planning, 2004. 